\title{
Analysis of Initial Baseline Clinical Parameters and Treatment Strategy Associated with Medication Failure in the Treatment of Benign Prostatic Hyperplasia in Korea
}

\author{
Hoon Choi, Young-Seop Chang, Jin-Bum Kim, Seok Ho Kang ${ }^{1}$, Hong Seok Park ${ }^{1}$, Jeong Gu Lee \\ Department of Urology, Konyang Universtiy College of Medicine, Daejeon; \\ ${ }^{1}$ Department of Urology, Korea University School of Medicine, Seoul, Korea
}

\begin{abstract}
Purpose: To analyze the baseline clinical factors and medication treatment strategy used in cases with medication treatment failure of benign prostatic hyperplasia (BPH).

Methods: From January 2006 to December 2009, 677 BPH patients with at least 3 months of treatment with medication were enrolled. We analyzed clinical factors by medication failure $(n=161)$ versus maintenance $(n=516)$, by prostate size (less than $30 \mathrm{~g}$, $\mathrm{n}=231 ; 30$ to $50 \mathrm{~g}, \mathrm{n}=244$; greater than $50 \mathrm{~g}, \mathrm{n}=202$ ), and by prostate-specific antigen (PSA) levels (less than $1.4 \mathrm{ng} / \mathrm{mL}$, $\mathrm{n}=324$; more than $1.4 \mathrm{ng} / \mathrm{mL}, \mathrm{n}=353$ ).

Results: Age, combination medication rate, PSA, and prostate volume were statistically different between the medication treatment failure and maintenance groups. By prostate size, the PSA and medication failure rates were relatively higher and the medication period was shorter in patients with a prostate size of more than $30 \mathrm{~g}$. The combination medication rate was higher in patients with a prostate size of more than $50 \mathrm{~g}$. The medication failure rate and prostate volume were higher in patients with a PSA level of more than $1.4 \mathrm{ng} / \mathrm{mL}$. However, the combination treatment rate was not significantly different in patients with a PSA level lower than $1.4 \mathrm{ng} / \mathrm{mL}$. Suggestive cutoffs for combination medication are a prostate volume of $34 \mathrm{~g}$ and PSA level of $1.9 \mathrm{ng} / \mathrm{mL}$. Conclusions: The clinical factors associated with medication failure were age, treatment type, and prostate volume. Combination therapy should be considered more in Korea in patients with a PSA level higher than $1.4 \mathrm{ng} / \mathrm{mL}$ and a prostate volume of between 30 and $50 \mathrm{~g}$ to prevent medication failure.
\end{abstract}

Keywords: Benign prostatic hyperplasia; Combination medication; Medication failure

\section{INTRODUCTION}

Over the past decade, there has been a significant decline in the frequency of surgery to manage the symptoms associated with benign prostatic hyperplasia (BPH). Medication therapy is now the most common treatment option used in clinical practice. Knowledge of the progressive nature and the risk of $\mathrm{BPH}$ progression are increasing. Our understanding of the pharmacological effects of $\mathrm{BPH}$ continues to evolve, so there are an increasing number of therapeutic choices for individual patients with BPH. Currently, most patients who visit a urologist for lower urinary tract symptoms (LUTS) are given empirical treatment with an alpha-adrenergic blocker ( $\alpha$-blocker) either with or without a 5-alpha reductase inhibitor (5-ARI). It is important for clinicians to determine which patients are at increased risk for disease progression in order to provide optimal therapy and a treatment approach consistent with patient preferences.

Uncontrolled disease progression is characterized by aggravation of symptoms, deterioration of the urinary flow rate, increase in prostate volume, and the need for BPH-related surgery. Numerous factors have been shown to be linked to the risk of $\mathrm{BPH}$ progression [1]. Although treatment with $\alpha$-blockers and
Corresponding author: Jeong Gu Lee

Department of Urology, Korea University Anam Hospital, Korea University School of Medicine, Anam-dong 5-ga, Seongbuk-gu, Seoul 136-705, Korea Tel: +82-02-920-5683 / Fax: +82-02-928-7864 / E-mal: jeongkl@kumc.or.kr Submitted: December 10, 2010 / Accepted after revision: December 23, 2010
This is an Open Access article distributed under the terms of the Creative Commons Attribution Non-Commercial License (http://creativecommons.org/licenses/by-nc/3.0/) which permits unrestricted non-commercial use, distribution, and reproduction in any medium, provided the original work is properly cited. 
5-ARIs usually results in improvement in symptoms and uroflowmetric parameters, the rate of medication failure and the probability of a patient requiring surgery remain unknown. The goal of this study was to determine the baseline factors associated with medication failure in patients with symptomatic BPH and the treatment strategy used for BPH management.

\section{MATERIALS AND METHODS}

From January 2006 to December 2009, we reviewed the medical records of all male patients presenting with LUTS under the approval of a relevant ethics committee. After routine initial baseline studies, 677 patients who were diagnosed with BPH and who had received at least 3 months of medication were enrolled. Patients were excluded from the study if they had bladder surgery, urethral surgery, previous prostate surgery, or a prostate malignancy. Patients with strictly controlled diabetes or hepatic, renal, or cardiovascular dysfunction without complications were included. All patients were prescribed $\alpha$-blockers and/or 5-ARI. The rates of patient were checked into alphablocker monotheraphy and $\alpha$-blockers plus 5-ARI combination medication. The dosage of the $\alpha$-blocker was determined by titration at biweekly intervals over 8 weeks to reach maximum efficacy. We initially determined the International Prostate Symptom Score (IPSS), maximum uroflow rate (Qmax), prostate volume, postvoid residual urine volume (PVR), blood urea nitrogen (BUN), creatinine, and PSA levels as the clinical baseline factors. Each eligible patient was asked to fill out the IPSS questionnaire. The maximum urinary flow rate $(\mathrm{mL} / \mathrm{sec})$ was measured by uroflowmetry. PVR $(\mathrm{mL})$ was measured by use of diagnostic ultrasound. The prostate volume $(\mathrm{mL})$ was measured and an integrated volumetric program automatically calculated the volume by using the following formula: volume $1 / 4$ width $\times$ length $\times$ height $\times 0.5236$ [2].

During the follow-up, the medication failure group was defined as patients in whom surgical treatment was performed, especially transurethral surgery in patients who declined further medical treatment or patients who had spontaneous acute urinary retention (AUR) and required suprapubic or urethral catheterization. The medication maintenance group included patients who did not require surgical or AUR treatment and the ration of medication maintenance or failure were also analyzed. In addition, comparison was made across tertile distributions of prostate size defined by weight; the following categories were evaluated: less than $30 \mathrm{~g}, 30$ to $50 \mathrm{~g}$, and $50 \mathrm{~g}$ or greater. Further- more, comparison of stratified by PSA levels was performed with the cutoff of $1.4 \mathrm{ng} / \mathrm{mL}$. All the variables: uroflometric parameters and symptom scores were included in the analysis by prostate volume and PSA.

Data entry and statistical analyses were performed with SPSS ver. 12.0 (SPSS Inc., Chicago, IL, USA). Baseline values of the clinical factors were analyzed by using the independent $t$-test, Pearson chi-square test, ANOVA test, and Kaplan Meier plot graphically. A logistic regression analysis was used to determine the baseline clinical factors, and receiver operating characteristic (ROC) curves were used to determine the cutoff values for prostate volume and PSA associated with medication failure.

\section{RESULTS}

Among 677 patients, 516 patients maintained medical treatment over 3 months and 161 patients were classified as the medication failure group. Of the patients in the medication failure group, 92 patients (60.8\%) underwent BPH-related surgery due to insufficient response to medication or patient preference and 69 patients (39.2\%) developed AUR.

The patient demographics are shown in Table 1. The medication failure group was older than the medication maintenance group (66.4 vs. 62.2 years), but there were no significant differences in their medical disease history. Among the enrolled patients, 407 patients (60.1\%) had received $\alpha$-blocker monotherapy and 270 patients (39.9\%) had received combination medication ( $\alpha$-blocker and 5-ARI); the frequency of combination medication was higher in the medication failure group. The medical treatment period was longer in the medication maintenance group (16.4 vs. 9.4 months).

At baseline, the initial IPSS, prostate volume, transitional zone volume, and PVR were higher and the Qmax was lower in the medication failure group. The results of the logistic analysis for medication failure are shown in Table 2. Age, treatment type, and prostate volume were statistically significant factors associated with medication failure for BPH.

We analyzed clinical factors by prostate volume (less than 30 g, $\mathrm{n}=231 ; 30$ to $50 \mathrm{~g}, \mathrm{n}=244$; greater than $50 \mathrm{~g}, \mathrm{n}=202$ ) and by PSA level (less than $1.4 \mathrm{ng} / \mathrm{mL}, \mathrm{n}=324$; more than $1.4 \mathrm{ng} / \mathrm{mL}$, $\mathrm{n}=353$ ). The analysis by prostate volume is shown in Table 3 . Age, PSA level, and cases of medication failure were higher and the medication period was shorter in patients with prostate volumes over $30 \mathrm{~g}$. The percentage of patients receiving combination treatment was higher among patients with prostate sizes of 
more than $50 \mathrm{~g}$ than in the other groups.

Comparison of the variables stratified by PSA level with the cutoff of $1.4 \mathrm{ng} / \mathrm{mL}$ showed that age and the number of cases of medication failure, as well as prostate volume, were relatively high among patients with PSA levels greater than $1.4 \mathrm{ng} / \mathrm{mL}$ (Table 4). The paramount cutoff value for medication failure of prostate volume (area under the ROC curve, 0.68 ) was $34 \mathrm{~g}$, with a sensitivity of 0.73 and a specificity of 0.52 , and that of PSA (area under ROC curve 0.70) was $1.9 \mathrm{ng} / \mathrm{mL}$, with a sensi-

Table 1. Baseline clinical values of BPH patients: comparison between medical treatment failure and medication maintenance group

\begin{tabular}{lccc}
\hline Parameters & $\begin{array}{c}\text { Medical } \\
\text { treatment } \\
\text { failure group }\end{array}$ & $\begin{array}{c}\text { Medical } \\
\text { treatment } \\
\text { maintenance } \\
\text { group }\end{array}$ & P-value \\
\hline Patients & 161 & 516 & $0.02^{\text {a) }}$ \\
Age (yr) & $66.4 \pm 7.4^{\text {a) }}$ & $62.2 \pm 7.7$ & 0.17 \\
Medical disease cases & $36(22.7)$ & $98(18.9)$ & $0.00^{\text {a) }}$ \\
Medication period (mo) & $9.4 \pm 7.9$ & $16.8 \pm 9.1^{\text {a) }}$ & $0.00^{\text {a) }}$ \\
Medication type & & & \\
$\quad$ Alpha-blocker & $65(40.4)$ & $342(66.3)$ & \\
$\quad$ monotheraphy & $96(59.6)^{\text {a) }}$ & $174(33.7)$ & \\
$\quad$ Combination therapy & $21.8 \pm 6.5$ & $16.4 \pm 7.1$ & $0.01^{\text {a) }}$ \\
Initial IPSS & $16.3 \pm 4.2$ & $15.9 \pm 4.4$ & 0.81 \\
BUN (mg/dL) & $1.1 \pm 0.3$ & $1.0 \pm 0.2$ & 0.51 \\
Creatinine (mg/dL) & $3.1 \pm 0.4$ & $1.5 \pm 0.3$ & $0.04^{\text {a) }}$ \\
PSA (ng/mL) & $10.1 \pm 5.7$ & $12.0 \pm 2.7^{\text {a) }}$ & $0.04^{\text {a) }}$ \\
Qmax (mL/sec) & $59.0 \pm 37.5^{\text {a) }}$ & $46.0 \pm 38.2$ & $0.00^{\text {a) }}$ \\
Residual vol (mL) & $52.4 \pm 21.9^{\text {a) }}$ & $32.1 \pm 19.0$ & $0.00^{\text {a) }}$ \\
Prostate vol (g) & & & \\
\hline
\end{tabular}

Values are presented as mean \pm SD or number (\%).

$\mathrm{BPH}$, benign prostatic hyperplasia; IPSS, International Prostate Symptom Score; BUN, blood urea nitrogen; PSA, prostate-specific antigen; Qmax, maximum uroflow rate.

a) $\mathrm{P}$-value $<0.05$. tivity of 0.74 and a specificity of 0.58 . The probability of cumulative medication failure in patients with regard to a prostate volume of $34 \mathrm{~g}$ and a PSA level of $1.9 \mathrm{ng} / \mathrm{mL}$ are shown by Kaplan Meier plot in Fig. 1.

\section{DISCUSSION}

$\mathrm{BPH}$ is a chronic, complex disease that is commonly associated with annoying symptoms of the lower urinary tract. Although

Table 3. Comparative study stratified by prostate volume in $\mathrm{BPH}$ patients

\begin{tabular}{|c|c|c|c|c|}
\hline & $<30 \mathrm{~g}$ & $30-50 \mathrm{~g}$ & $>50 \mathrm{~g}$ & $\mathrm{P}$-value \\
\hline Patients & 231 & 244 & 202 & \\
\hline Age (yr) & $64.4 \pm 7.3$ & $67.2 \pm 7.2^{\mathrm{a})}$ & $68.7 \pm 7.7^{\text {a) }}$ & $0.00^{\mathrm{a})}$ \\
\hline $\begin{array}{l}\text { Medication failure } \\
\text { cases }\end{array}$ & $22(9.5)$ & $63(25.8)$ & $76(37.6)$ & $0.00^{\mathrm{a})}$ \\
\hline $\begin{array}{l}\text { Medical disease } \\
\text { cases }\end{array}$ & $38(40.4)$ & $44(66.3)$ & $52(66.3)$ & 0.56 \\
\hline $\begin{array}{l}\text { Medication period } \\
(\mathrm{mo})\end{array}$ & $12.4 \pm 7.9$ & $14.6 \pm 4.6$ & $15.2 \pm 6.3$ & 0.17 \\
\hline Medication type & & & & $0.01^{\text {a) }}$ \\
\hline $\begin{array}{l}\text { Alpha-blocker } \\
\text { monotheraphy }\end{array}$ & $164(71.0)$ & $156(63.9)$ & $87(43.1)$ & \\
\hline $\begin{array}{l}\text { Combination } \\
\text { therapy }\end{array}$ & $67(29.0)$ & $88(36.1)$ & $115(56.9)$ & \\
\hline Initial IPSS & $15.7 \pm 4.9$ & $16.4 \pm .3 .9$ & $17.8 \pm .4 .2$ & 0.32 \\
\hline BUN (mg/dL) & $15.1 \pm 0.4$ & $17.3 \pm 0.3$ & $16.2 \pm 0.3$ & 0.51 \\
\hline Creatinine $(\mathrm{mg} / \mathrm{dL})$ & $1.1 \pm 0.2$ & $1.0 \pm 0.3$ & $1.1 \pm 0.2$ & 0.64 \\
\hline PSA (ng/mL) & $1.0 \pm 0.3$ & $2.4 \pm 0.4$ & $2.9 \pm 0.3$ & $0.04^{\mathrm{a})}$ \\
\hline $\mathrm{Qmax}(\mathrm{mL} / \mathrm{sec})$ & $12.1 \pm 4.7$ & $11.2 \pm 3.4$ & $10.8 \pm 4.5$ & 0.21 \\
\hline Residual vol (mL) & $48.6 \pm 14.6$ & $56.3 \pm 12.8$ & $61.3 \pm 15.2$ & 0.11 \\
\hline
\end{tabular}

Values are presented as mean \pm SD or number (\%).

$\mathrm{BPH}$, benign prostatic hyperplasia; IPSS, International Prostate Symptom Score; BUN, blood urea nitrogen; PSA, prostate-specific antigen; Qmax, maximum uroflow rate.

a) $\mathrm{P}$-value $<0.05$.

Table 2. Multivariate analysis of the variables associated with medical treatment failure in patients with BPH

\begin{tabular}{lllllllll}
\hline & Age $(\mathrm{yr})$ & $\begin{array}{c}\text { Medication } \\
\text { period (mo) }\end{array}$ & $\begin{array}{c}\text { Medication } \\
\text { type }\end{array}$ & $\begin{array}{c}\text { Initial } \\
\text { IPSS }\end{array}$ & $\begin{array}{c}\text { PSA } \\
(\mathrm{ng} / \mathrm{mL})\end{array}$ & $\begin{array}{c}\text { Qmax } \\
(\mathrm{mL} / \mathrm{sec})\end{array}$ & $\begin{array}{c}\text { Residual vol } \\
(\mathrm{mL})\end{array}$ & $\begin{array}{c}\text { Prostate vol } \\
(\mathrm{g})\end{array}$ \\
\hline Odds ratio & 1.030 & 0.937 & 0.968 & 0.987 & 1.026 & 0.979 & 0.971 & 1.032 \\
95\% CI & $1.002-1.041$ & $0.879-1.023$ & $1.021-1.054$ & $0.925-1.106$ & $1.023-1.041$ & $0.913-1.015$ & $0.885-1.064$ & $1.011-1.052$ \\
P-value & $0.04^{\mathrm{a})}$ & 0.07 & $0.00^{\mathrm{a})}$ & 0.10 & $0.01^{\mathrm{a})}$ & 0.19 & 0.09 & $0.00^{\mathrm{a})}$ \\
\hline
\end{tabular}

BPH, benign prostatic hyperplasia; IPSS, International Prostate Symptom Score; PSA, prostate-specific antigen; Qmax, maximum uroflow rate; CI, confidence interval.

a) $\mathrm{P}$-value $<0.05$. 
Table 4. Comparative study stratified by the PSA cut off level of $1.4(\mathrm{ng} / \mathrm{mL})$ in patients with $\mathrm{BPH}$

\begin{tabular}{|c|c|c|c|}
\hline Parameters & $\begin{array}{l}<\text { PSA } 1.4 \\
(\mathrm{ng} / \mathrm{mL})\end{array}$ & $\begin{array}{l}\geq \text { PSA } 1.4 \\
(\mathrm{ng} / \mathrm{mL})\end{array}$ & $\mathrm{P}$-value \\
\hline Patients & 324 & 353 & \\
\hline Age (yr) & $64.6 \pm 7.7$ & $67.9 \pm 7.4$ & $0.02^{\mathrm{a})}$ \\
\hline Medication failure cases & $43(17.6)$ & $118(27.3)$ & $0.01^{\text {a) }}$ \\
\hline Medical disease & $56(22.9)$ & $78(18.1)$ & 0.17 \\
\hline Medication period (mo) & $12.6 \pm 8.1$ & $13.2 \pm 3.2$ & 0.23 \\
\hline Medication type & & & 0.11 \\
\hline $\begin{array}{l}\text { Alpha-blocker } \\
\text { monotheraphy }\end{array}$ & $198(61.1)$ & $209(59.2)$ & \\
\hline Combination therapy & $126(38.9)$ & $144(40.8)$ & \\
\hline Initial IPSS score & $17.7 \pm 6.5$ & $18.5 \pm 7.1$ & 0.27 \\
\hline BUN (mg/dL) & $16.3 \pm 4.2$ & $15.9 \pm 4.4$ & 0.81 \\
\hline Creatinine (mg/dL) & $1.1 \pm 0.7$ & $1.1 \pm 0.8$ & 0.40 \\
\hline $\mathrm{Qmax}(\mathrm{mL} / \mathrm{sec})$ & $11.1 \pm 7.8$ & $12.3 \pm 7.0$ & 0.14 \\
\hline Residual vol (mL) & $42.0 \pm 32.4$ & $56.0 \pm 36.4$ & $0.03^{\text {a) }}$ \\
\hline Prostate vol (g) & $41.4 \pm 19.4$ & $49.2 \pm 18.2$ & $0.03^{\text {a) }}$ \\
\hline
\end{tabular}

Values are presented as mean \pm SD or number (\%).

PSA, prostate-specific antigen; $\mathrm{BPH}$, benign prostatic hyperplasia; IPSS, International Prostate Symptom Score; BUN, blood urea nitrogen; Qmax, maximum uroflow rate.

a) $\mathrm{P}$-value $<0.05$

medication provides an improvement in symptoms and uroflowmetric parameters in patients with $\mathrm{BPH}$, the frequency of medical treatment failure and crossover to surgery remain unknown. BPH can progress to cause severe complications such as AUR and BPH-related surgery [3]. In a survey conducted of men with BPH in five European countries, $58 \%$ and $56 \%$ of patients were 'fairly' and 'very' concerned about potential complications such as AUR and prostate-related surgery, respectively. Reducing the likelihood of requiring surgery was the most anticipated treatment outcome. In other words, the risk for surgery or AUR was a greater concern for patients than other factors such as symptom relief or quality of life $[4,5]$.

Although both surgery and medication treatment modalities are available for the management of $\mathrm{BPH}$, transurethral prostate surgery had been the most effective treatment for symptomatic BPH. Recently, however, there has been agreement on the efficacy of medication treatment.

Treatment with $\alpha$-blockers rapidly improves obstructive symptoms by relaxing the smooth muscles of the prostate and bladder neck, and 5-ARIs inhibit the conversion of testosterone
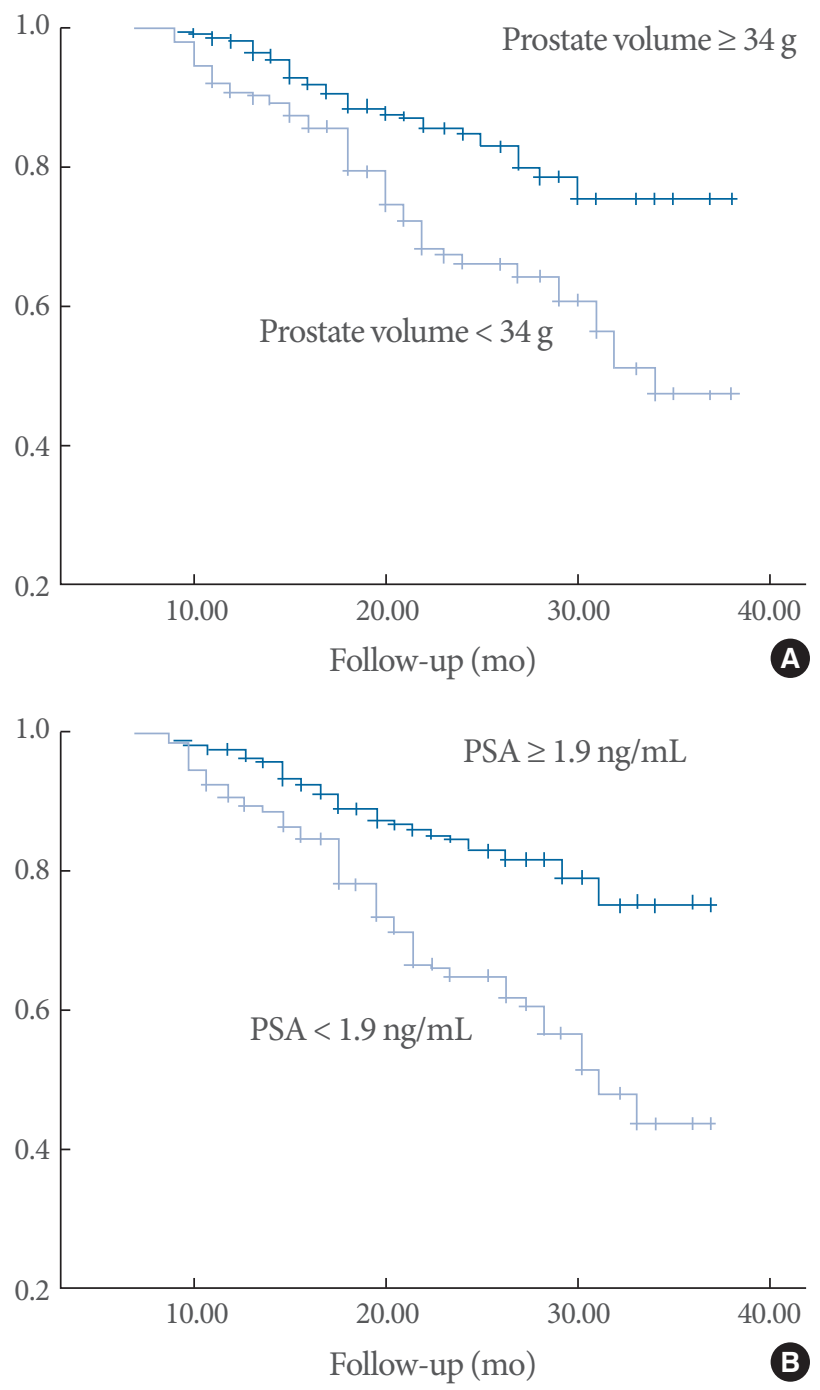

Fig. 1. Kaplan-Meier survival curve for the probability of cumulative incidences of medication failure. Comparison was made by prostate volume (A) and PSA (B). (A) Probability of cumulative incidences of medication failure by prostate volume of $34 \mathrm{~g}$. (B) Probability of cumulative incidence of medication failure by PSA level of $1.9 \mathrm{ng} / \mathrm{mL}$.

to dihydro-testosterone within the prostate and decrease the prostate volume. $\alpha$-Blockers can also induce apoptosis in the prostate glandular epithelium and stroma, by an unknown mechanism, but do not significantly reduce the cumulative incidence of invasive therapy, and large studies have failed to show any effect of $\alpha$-blockers on prostate volume. In one study, doxazosin reduced the risk of symptomatic progression by $45 \%$ compared with placebo and delayed the time to AUR. However, it did not considerably reduce the cumulative frequency of AUR at 4 years compared with placebo. In a survey of men treated 
with finasteride, the relative risk of AUR was reduced by $57 \%$, which was more than in men treated with a placebo $(7 \%)[3,6]$. Similarly, dutasteride studies have shown a reduced relative risk of AUR (57\%) and surgical intervention (48\%) compared with placebo at 2 years [7]. These effects could be explained by the prostate volume-reducing effects of 5-ARI. In another study, finasteride reduced prostate volume by $18 \%$ compared with a $14 \%$ increase with placebo [8].

Current European Association of Urology guidelines for the management of BPH reflect this by stating that PSA, as a parameter for prostate volume, can be used to evaluate the risks of either requiring surgery or developing AUR [9]. Serum PSA is easily measured in clinical practice and can therefore facilitate the identification of those men with $\mathrm{BPH}$ at risk for disease progression and help to guide therapeutic decisions. Although the precise relationship between PSA and prostate growth may vary from one individual to another, analysis of the data showed that PSA thresholds for detecting a prostate volume $\geq 30$ g were $\geq 1.3 \mathrm{ng} / \mathrm{mL}, \geq 1.5 \mathrm{ng} / \mathrm{mL}$, and $\geq 1.7 \mathrm{ng} / \mathrm{mL}$ in men with BPH in the 50 to 59 -, 60 to 69 -, and 70 to 79 -year-old age groups [10].

Many studies have focused on the PSA threshold levels of 1.4 or $2.0 \mathrm{ng} / \mathrm{mL}$ to identify patients at high risk for $\mathrm{BPH}$ progression. Our study also showed differences in age, the medication treatment failure rate, and prostate size according to the cutoff of $1.4 \mathrm{ng} / \mathrm{mL}$. However, the treatment pattern with regard to the frequency of combination therapy was not significantly different between the two groups. Therefore, there were discrepancies with the updated current protocols. Finasteride in combination with terazosin, doxazosin, or alfuzosin failed to show a benefit in the patients receiving combination therapy over placebo or alpha-blocker monotherapy in terms of improving the Qmax; in addition, in this study it did not show a correlation with medication failure [11].

Prostate volume is perhaps the most extensively studied of the risk factors for BPH progression. Men with a prostate volume of $\geq 30 \mathrm{~g}$ are more likely to have moderate-to-severe symptoms (3.5-fold increase), decreased flow rates (2.5-fold increase), and AUR (three- to fourfold increase) than are men with a prostate volume $<30 \mathrm{~g}$ [8]. Jacobsen et al. [12] reported that if the prostate volume was larger than $30 \mathrm{~g}$, the incidence of AUR was increased at least threefold. In clinical practice, however, the volume guidelines for combination medication were vague and between $30 \mathrm{~g}$ and $50 \mathrm{~g}$. We analyzed prostate volume and treatment protocol. There was a relatively high frequency of patients in the medical failure group among men with a prostate volume of more than $30 \mathrm{~g}$. However, the frequency of combination treatment was higher only in men with a prostate volume of more than $50 \mathrm{~g}$. Therefore, the men with prostate volumes in the $30 \mathrm{~g}$ to $50 \mathrm{~g}$ range received a relatively lower rate of combination therapy, but had a similar rate of medication failure. Because adverse effects (erectile dysfunction, ejaculatory disorders, and decreased libido) are more common with combination therapy than with monotherapy, patients and/or treating physicians hesitate to use 5-ARI combination treatment. Korean people are more afraid of the side effects related to these sexual problems, and our results are a reflection of such inclinations. On the other hand, several studies have reported low levels of confidence with 5-ARI for the treatment of BPH. For example, Lepor et al. [13] concluded that finasteride alone or in combination with terazosin was no more effective than placebo or terazosin alone. The reason for the high rate of combination treatment in the medication failure group is that these patients usually include those who were candidates for BPH-related surgery due to their high prostate volumes. However, many patients with intermediately enlarged prostates might not be treated with combination therapy, even though they have a high rate of medication failure.

Choosing the patients who will benefit from medication and determining the most effective course of treatment continue to be topics of study. Patients should be presented with a reasonable estimate of their baseline risk of disease progression along with the risks and benefits of medication therapy and the need for combination medication so that a proper decision can be made. The results of the present study showed that the frequency of AUR and BPH-related surgery was significantly higher in patients receiving 5-ARI combination therapy because of their high prostate volumes. Prostate volume appeared to be the most significant associated factor; it was related to both age and the PSA level. However, it cannot be used alone as an independent factor to guide BPH treatment options. Other parameters such as the symptom score, PVR, or Q-max must also be considered. All treatments resulted in a significant improvement in the symptom scores, with combination therapy superior to a-blocker monotherapy [8]. Worsening of the PVR has been shown to be a good predictor of AUR in men with LUTS suggestive of BPH [14].

Derived from the ROC curve, cutoff values of prostate volume and PSA for predicting medical treatment failure were 34 $\mathrm{g}$ and $1.9 \mathrm{ng} / \mathrm{mL}$, respectively. We suggest that these cutoffs of prostate volume and PSA can be used in combination to coun- 
sel patients at their initial visit. Although our study was a retrospective study and included a limited number of cases, it has revealed the proper cutoffs for prostate volume and serum PSA level for combination treatment to be effective. Studies on the benefits of long-term combination treatment are needed, especially in patients with an intermediate increase in prostate and PSA levels.

In conclusion, age, medication treatment period, treatment type, and prostate volume were found to be risk factors for future surgery or AUR. Patients with a prostate volume of more than $30 \mathrm{~g}$ were more likely to be in the medication failure group. Combination treatment was relatively low for the patients with prostate volumes of less than $50 \mathrm{~g}$. Based on a PSA cutoff of 1.4 $\mathrm{ng} / \mathrm{mL}$, age, the medication failure rate, and prostate size differed, but the rate of combination therapy did not. Therefore, patients with a prostate volume of $30 \mathrm{~g}$ to $50 \mathrm{~g}$ and a PSA over $1.4 \mathrm{ng} / \mathrm{mL}$ should be considered for combination therapy more often to prevent medication failure in Korea. Additionally, our suggestive cutoff values are a prostate volume of $34 \mathrm{~g}$ and a PSA level over $1.9 \mathrm{ng} / \mathrm{mL}$.

\section{CONFLICT OF INTEREST}

No potential conflict of interest relevant to this article was reported.

\section{REFERENCES}

1. Roehrborn CG. Benign prostatic hyperplasia: an overview. Rev Urol 2005;7 Suppl 9:S3-14.

2. Hong SJ, Ko WJ, Kim SI, Chung BH. Identification of baseline clinical factors which predict medical treatment failure of benign prostatic hyperplasia: an observational cohort study. Eur Urol 2003;44: 94-9.

3. McConnell JD, Bruskewitz R, Walsh P, Andriole G, Lieber M, Holtgrewe HL, et al. The effect of finasteride on the risk of acute urinary retention and the need for surgical treatment among men with benign prostatic hyperplasia. Finasteride Long-Term Efficacy and Safety Study Group. N Engl J Med 1998;338:557-63.

4. Emberton M, Marberger M, de la Rosette J. Understanding patient and physician perceptions of benign prostatic hyperplasia in Europe: The Prostate Research on Behaviour and Education (PROBE)
Survey. Int J Clin Pract 2008;62:18-26.

5. Emberton M, Cornel EB, Bassi PF, Fourcade RO, Gomez JM, Castro R. Benign prostatic hyperplasia as a progressive disease: a guide to the risk factors and options for medical management. Int J Clin Pract 2008;62:1076-86.

6. MacDonald R, Wilt TJ. Alfuzosin for treatment of lower urinary tract symptoms compatible with benign prostatic hyperplasia: a systematic review of efficacy and adverse effects. Urology 2005;66: 780-8.

7. Roehrborn CG, Boyle P, Nickel JC, Hoefner K, Andriole G; ARIA3001 ARIA3002 and ARIA3003 Study Investigators. Efficacy and safety of a dual inhibitor of 5-alpha-reductase types 1 and 2 (dutasteride) in men with benign prostatic hyperplasia. Urology 2002;60:434-41.

8. McConnell JD, Roehrborn CG, Bautista OM, Andriole GL Jr, Dixon CM, Kusek JW, et al. The long-term effect of doxazosin, finasteride, and combination therapy on the clinical progression of benign prostatic hyperplasia. N Engl J Med 2003;349:2387-98.

9. Madersbacher S, Alivizatos G, Nordling J, Sanz CR, Emberton M, de la Rosette JJ, et al. EAU 2004 guidelines on assessment, therapy and follow-up of men with lower urinary tract symptoms suggestive of benign prostatic obstruction (BPH guidelines). Eur Urol 2004;46:547-54.

10. Anderson JB, Roehrborn CG, Schalken JA, Emberton M. The progression of benign prostatic hyperplasia: examining the evidence and determining the risk. Eur Urol 2001;39:390-9.

11. Kirby RS, Roehrborn C, Boyle P, Bartsch G, Jardin A, Cary MM, et al. Efficacy and tolerability of doxazosin and finasteride, alone or in combination, in treatment of symptomatic benign prostatic hyperplasia: the Prospective European Doxazosin and Combination Therapy (PREDICT) trial. Urology 2003;61:119-26.

12. Jacobsen SJ, Jacobson DJ, Girman CJ, Roberts RO, Rhodes T, Guess HA, et al. Natural history of prostatism: risk factors for acute urinary retention. J Urol 1997;158:481-7.

13. Lepor H, Williford WO, Barry MJ, Brawer MK, Dixon CM, Gormley $\mathrm{G}$, et al. The efficacy of terazosin, finasteride, or both in benign prostatic hyperplasia. Veterans Affairs Cooperative Studies Benign Prostatic Hyperplasia Study Group. N Engl J Med 1996;335:533-9.

14. Roehrborn CG, Malice M, Cook TJ, Girman CJ. Clinical predictors of spontaneous acute urinary retention in men with LUTS and clinical BPH: a comprehensive analysis of the pooled placebo groups of several large clinical trials. Urology 2001;58:210-6. 